\title{
How Environment Can Reveal Semantic Capacities in Nonhuman Animals
}

\author{
Heidi Lyn* and Jennie L. Christopher
}

Department of Psychology, University of South Alabama

*Corresponding author (Email: hlyn@ southalabama.edu)

Citation - Lyn, H., \& Christopher, J. L. (2020). How environment can reveal semantic capacities in nonhuman animals. Animal Behavior and Cognition, 7(2), 159-167. doi: https://doi.org/10.26451/abc.07.02.10.2020

\begin{abstract}
Seyfarth, Cheney, and Marler (1980) were the first researchers to delineate a nonhuman animal communication system that seemed to include linguistic reference (signals with specific meanings). Arguments continue, however, over the use of linguistic terms as well as the specific nature of those calls. Frequently dismissed or ignored in the discussion of the usefulness of animal communication to the study of human language evolution is the wealth of data from the language research projects that show remarkable levels of symbolic behavior in animals reared in enriched, enculturated environments. These data show that the capacity for semantic communication systems is not unique to humans. Discussions surrounding semanticity and human language evolution would therefore benefit by switching focus to the environmental factors that support the expression of biologically extant semantic capacities.
\end{abstract}

Keywords - Symbolic, Ape language research, Evolution of language, Semanticity

Human language is an infinitely complex method of communication unknown outside of our own species but is based and rooted in semantics - that is, the use of meaningful symbols (e.g., Deacon, 1997; Fitch, 2005). The search for the evolutionary trajectory of human language has included a search for precursors of various components of human language in other species, including semanticity. For many years, nonhuman animal signals were assumed to be merely an expression of the individual's internal motivational or affective state (Smith, 1977), while true symbol use was presumed to be unique to humans (e.g., Hockett, 1960; Smith \& Kirby, 2008). Predictably, when Seyfarth et al. (1980) claimed evidence of semantic signal use in a nonhuman species, the backlash from the scientific community was immediate with strong objections to the use of linguistic terms in describing communication in an animal (see Deacon, 1997, and Fitch, 2005, for discussions of the backlash).

Arguments for and against semanticity often surround the definition of signals as symbolic, iconic, or indexical. Symbols were historically described as signals that "refer to" or "stand for" something in the external world (e.g., see writings by Peirce (1839-1914) Collections of Peirce's Writings, n.d.). This definition is not completely adequate because iconic and/or indexical signals also refer directly to items in the external world, at least in the sense that they are associated with those referents, Symbols, though, are the only signals that are thought to "stand for" the external referent and to be associated with a fully-formed mental representation of the referent. The challenge has been to determine what level of representation resides in the minds of nonverbal animals. 
Current definitions of symbols require that these signals are purely arbitrary, culturally defined signals that provoke mental representations of objects, actions, events, etc. (Deacon, 1997; Fitch, 2010; Hockett, 1960). Other requirements for symbolicity have also been suggested: that the symbol must evoke the referent in its physical absence and without contextual or behavioral cues (Roitblat et al., 1993). For example, when a two-year-old child says "ball", we assume that they have a round, bouncy plaything in their mind - it could be present or not, they could be asking for a ball, pointing out a ball, telling a story about someone else's ball, or referring to any one of an infinite variety of contexts. These types of referential symbols are also inherently categorical in nature, as "ball" does not refer to a specific ball, but rather a class or category of objects that share characteristics - in this case, usually round, bouncy and a toy. Similarly, Deacon (1997) argues that true symbolicity is only driven through the relationships between invisible or unreal referents; that it is the relationship between these shared, but purely mental concepts that denotes a true symbol (see also Fitch, 2010).

Iconic symbols, in contrast, are associated with the referent through physical or acoustic similarity. For example, onomatopoetic sounds in human languages (e.g., bang, meow) are considered iconic because they resemble sudden sounds and animal noises, rather than being an arbitrary sound. These signals are inherently less flexible, but can also refer to objects, action, etc. in their absence. They are, however, not regarded as culturally transmitted as they are not arbitrary and the mental representations they provoke are presumably based on triggering the similarities between signal and referent.

Indexical signals are those that are linked with the referent in space and/or time. The most classic example is seeing smoke and understanding that nearby there is a fire. Although human language is rich with indexical signaling (e.g., see Curtin, 2009), in animal communication, indexical symbols are considered to be the simplest of associative mechanisms (e.g., Deacon, 1997; Wheeler \& Fischer, 2012). Indexes can be achieved through classical conditioning, for instance. The case of Pavlov's dogs learning to anticipate food because of the approaching footsteps of the researcher is a good example. The footsteps serve as an indexical signal for food, but do not necessarily provoke mental representation of the referent, although such representation is not precluded. Indexical signals are individually learned, usually through classical or operant conditioning. Therefore, some forms of indexical signals are simply conditioned responses.

In their classic paper Seyfarth et al. (1980) specifically argued for semanticity in vervet monkeys. They provided evidence for three separate vervet vocal calls that "referred" to three different predators. In addition, in this and later papers, they ran a series of groundbreaking experiments designed to provide further evidence for the semantic (or referential) nature of the calls. For example, experiments included data on audience effects, flexible responses, responses to playback in absence of the actual referent, etc. Other researchers, however, argued that the use of linguistic language such as semanticity was unwarranted - reasoning included wariness of anthropomorphism (Owings \& Morton 1997; Owren \& Rendall 1997; Smith 1981) and a recognition of the lack of evidence regarding the mechanisms underlying the vocalizations (Macedonia \& Evans, 1993). In response to the controversy, Macedonia and Evans (1993) introduced the term 'functional reference' to distinguish animal calls from the 'linguistic reference' (semantics) of human language.

More recently, researchers have argued that even this terminology is unhelpful (Wheeler \& Fischer, 2012). Because most, if not all, primate vocalizations seem to be biologically hardwired (although see Manser, 2013; Taglialatela et al., 2012), newer arguments have suggested that primate vocals have little to nothing to tell us about human language evolution and researching functionally referential signals for this purpose is "more distracting than insightful" (Wheeler \& Fischer, 2012). These researchers suggest the term "Context-dependent" calls - highlighting the relative inflexibility of alarm calls (Wheeler \& Fischer, 2012), which are not utilized but in one specific context.

These kinds of arguments, unfortunately, frequently lead to responses that support discontinuity the argument that because primate vocalizations may not be a direct evolutionary path to human language, there are no human language precursors in nonhumans (see Fitch \& Zuberbühler, 2013; Lloyd, 2004; Lyn, 2017; Pepperberg, 2017, for examples and discussion). This line of argumentation is problematic in 
several ways. First, it assumes that only the production of language is of import and further implies that speech is the only meaningful route toward the evolution of language. However, many researchers both in and outside of the primate vocalization field have recognized that speech production is only part of language evolution with comprehension as well as vocal and gestural flexibility providing alternate potential paths to language as we know it (e.g., Burling, 1993; Janik \& Slater, 1997; Senghas, 2003, Wheeler \& Fischer, 2012). Several researchers even argue that the preponderance of data suggest that primate use of gesture and/or the combination of gesture and vocalization may be better candidates for language precursors than vocalization (Gillespie-Lynch et al., 2014; Goldin-Meadow, 1993; Taglialatela et al., 2011) This gestural focus retains the potential for elucidation of the origins of human language through the study of primate communication in spite of their limited innate vocal repertoires/abilities.

More importantly, if science is focused on vocal production in natural environments as the only avenue to study language, and the conclusion is that vocal production in natural environments has no bearing on language evolution, the most frequent conclusion is that nonhuman primates have no biological capacity for human language precursors. This logical progression ultimately leads to the search for the biological change that occurred to make symbol use (or syntax, or any other component of human language) possible. However, there is a wealth of data that show symbolic use and comprehension in nonhuman primates, the data just do not use the vocal modality, and are experimental, not naturalistic.

As the first author has argued elsewhere (Lyn, 2017), there is a strong tendency for current researchers to dismiss the findings of animal language research (ALR) due to biases against human interaction within communication research (also see Pepperberg, 2017). However, there remain only two ways to study the potential effects of human linguistic culture on communicative abilities: one is to raise human children without it, and the other is to raise nonhumans with it. These animal language studies remain the only ethical way to separate the biological potential of animal communication from what those species typically display. Should animals show the capacity for learning flexible and complex semantic systems, one no longer needs to posit an evolutionary avenue for that capacity - instead, the question shifts to what environments support the expression of these capacities (Lyn, 2017).

The modern history of animal language experiments really began in the late 1960s when researchers turned from trying to teach apes to speak (attempts that unsurprisingly failed, given the limited vocal flexibility in most primate species), to using other communication systems (Lyn, 2012; Roitblat et al., 1993). Since then, these experiments have provided a great deal of data regarding how animals process semantic information. Across several studies, a number of chimpanzees (Pan troglodytes), bonobos (Pan paniscus), a gorilla (Gorilla gorilla), and an orangutan (Pongo pygmaeus) have been shown to use up to several hundred American Sign Language-based gestures or other visual symbols functionally (Gardner \& Gardner, 1969; Miles, 1994; Patterson \& Linden, 1981; Rumbaugh, 1977; Savage-Rumbaugh, 1986; Savage-Rumbaugh et al., 1986; Terrace, 1979). Other findings include meta-linguistics - the ability to answer questions about symbols and referents; discourse/conversations including appropriate responses to questions, behavioral concordance - stating a planned set of actions, then following through, and accurate performance on double-blind vocabulary tests (See Lyn, 2012 for a review of these and other ape language findings). These findings separately and together suggest, at minimum, that apes can create an arbitrary, culturally-determined association between symbol and referent and use it appropriately across many contexts and without behavioral cues.

Semantic findings of this kind are not limited to primates. At least one Grey parrot (Psittacus erithacus) has been shown to acquire spoken labels for objects, materials, colors, and numbers and to be able to answer questions appropriately (Pepperberg, 1999). Bottlenose dolphins (Tursiops truncatus) have also been shown to respond appropriately to arbitrary symbols (gestural and acoustic; Herman et al., 1984, 1993). These studies and others were specifically designed to answer questions about the symbolicity of the animals' responses. For instance, in response to the argument that symbols require appropriate responses in absence of the referent, Herman and Forestell (1985) designed a study in which the dolphin had to respond to commands referring to objects that were missing. In addition, when given anomalous sequences, the dolphin could spontaneously respond in ways that underscored the likely symbolic nature of their understanding. An excellent example occurred in the missing object task. The 
dolphin was given a series of questions - e.g., BALL QUESTION (Is the ball in the pool) to which she could respond by pressing one of two paddles - yes or no. When the dolphin was asked to bring one object to an object that was not there, she spontaneously brought the item to the no paddle. This was an untrained behavior with no reinforcement history, and so does not meet any standard for contextdependency. Underscoring this point, Herman et al. (1993) listed an extensive series of contexts in which the object symbols could provoke correct responses in the dolphins. These findings and others strongly indicate that these dolphins have a complex mental representation of the referent and symbol (Herman et al., 2001). As stated by the authors, the accuracy of the dolphin across behaviors and contexts "illustrate the richness with which the symbol ... stands for its real-word referent" (Herman et al., 1993, p. 434). Given flexible, arbitrary associations between signal and referent as well as mental representations of those referents, nonhuman animals have shown at least rudimentary symbolicity, according to most definitions.

However, there is even more evidence of nonhuman animal symbolicity in the literature. Two long-term studies performed at the Language Research Center (LRC) in Atlanta, Georgia (and now at the ACCI, in Des Moines, Iowa), have been even more successful at parsing what apes trained in symbol use (and later those raised in a language-enriched environment without specific training) can understand about both symbols and referents. Both series of studies (henceforth, LRC studies) utilized a keyboard of visuographic symbols called lexigrams (See Figure 1). Each lexigram represents a different word - for example: locations (colony room, office), ape names (Kanzi, Matata), foods (apple, orange juice), and actions (chase, go).

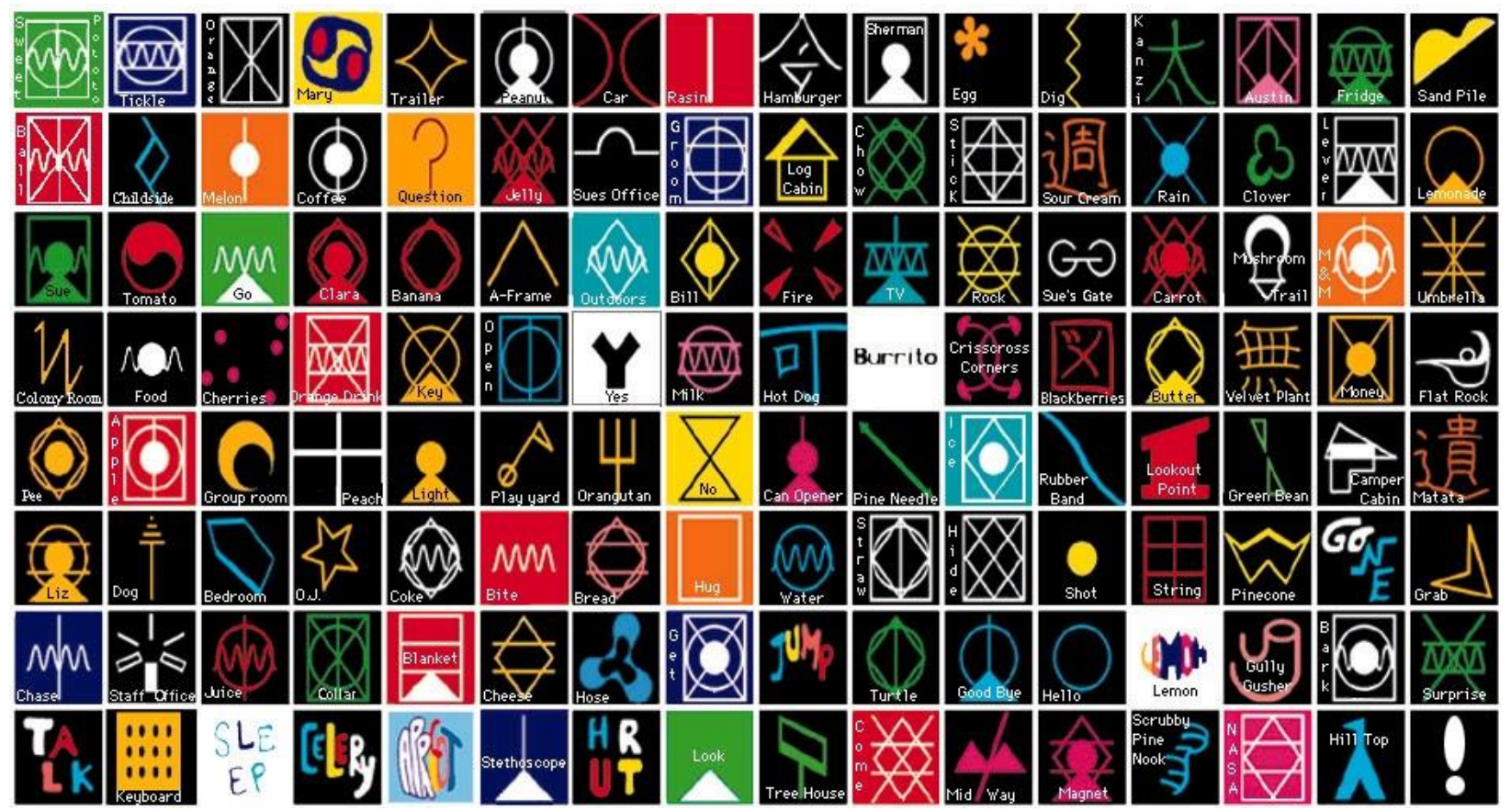

Figure 1. First panel of the lexigram keyboard used in later studies at the LRC. Photo used with permission from the LRC and Sue Savage-Rumbaugh.

The first series of LRC studies focused on two language-trained chimpanzees - Sherman and Austin. The chimps could use the symbol keyboard in fairly complicated ways, for example, in one study, one ape had to request a tool from the other and the other had to understand the request and retrieve the appropriate tool, pass it to the first chimp, who would then use the tool to retrieve food, which would then be shared (Savage-Rumbaugh et al., 1978). It should be noted, that Savage-Rumbaugh and colleagues wrote extensively on what would be required of a signal to be symbolic, even concluding that, in their own earlier work, lexigram use was likely not symbolic (Savage-Rumbaugh, 1986). In addition, this work 
was carried out in a climate in which critics and those that sought to dismiss these findings were vocal. In one instance, a claim was made that, using operant conditioning, pigeons could be taught the same sequence of behaviors as the chimps (Epstein et al., 1980). This study was a direct attempt to discredit the symbolicity in Savage-Rumbaugh's work. In a strong rebuttal, Savage-Rumbaugh and Rumbaugh (1980) enumerated the difference in the methodologies between the studies (including painstakingly teaching the pigeons behavioral steps that were inferred by the chimpanzees), but, more importantly to our point, noted the extreme flexibility in the chimpanzees' lexigram use, something not present in the pigeons' responses. The chimpanzees could use their symbols in multiple ways - requesting and naming referents, as well as offering a referent when it was requested on them. The pigeon's responses, in contrast, were contextuallybound, with no added meaning.

To experimentally explore further the symbolicity of the LRC communication system, SavageRumbaugh and colleagues also turned their attention to the question of mental representation. In a sometimes overlooked study, Savage-Rumbaugh et al. (1980) explored the potential concepts that accompanied the comprehension of lexigrams in chimpanzees. The study initially involved training the apes to sort referents into the categories of "Food" or "Tool" by placing each item into one of two boxes labelled with the category names. For example, an apple would be placed in the "Food" box and the key in the "tool" box. The apes were then tested with a wider range of referents and successfully sorted the untrained examples (all correctly, except for Sherman's one error: he sorted the sponge as a food. However, Sherman also liked to eat sponges). More importantly, in an untrained portion of the test, the chimpanzees were given paper labels with the lexigrams for these referents, the chimpanzees could then sort the lexigrams according to the properties of the referents, even though those referents were not in evidence. So, the lexigram for key would be placed in the tool box, and the lexigram for apple would be sorted with the foods. These were convincing data showing that detailed information about referents was accessible in the minds of the apes when exposed to symbols (Savage-Rumbaugh, 1981).

These were not the first data to show that apes could answer questions about referents. Premack and colleagues (e.g., Premack \& Premack, 1983) trained their chimpanzees to use plastic chips in order to study intelligence and conceptual knowledge. Their studies showed that chimpanzees could correctly answer questions such as "What color is apple?" (red), when the plastic chip was a different color (blue). These data were suggestive of referential knowledge, although several researchers were dubious, given the relatively few potential answers and the heavily operant nature of the training (see Ristau \& Robbins, 1982 for overview). However, the Premacks detailed many conceptual findings, including the concepts of same/different, large/small, name-of, shape-of, and size-of, indicating the biological capacity for learning these concepts is present in nonhumans.

In the later LRC studies, two bonobos (Kanzi and Panbanisha) and a chimpanzee (Panpanzee) learned functional use of lexigrams spontaneously - that is, without specific operant training (Brakke \& Savage-Rumbaugh, 1995, 1996; Savage-Rumbaugh et al., 1986). The apes' use of lexigrams was extremely flexible, making imperative, declarative, and interrogative statements. They used lexigrams in many different contexts, and in the absence of the physical referent. These three apes also comprehended the English counterparts to their lexigrams, with Kanzi performing similarly to a $2 \frac{1}{2}$ year old child on a test of English sentence comprehension (Savage-Rumbaugh et al., 1993). Analysis of over 100,000 utterances indicated a variety of cognitive abilities associated with their lexigram use, including mental time travel in their statements of past and future events (Lyn, Greenfield, Savage-Rumbaugh et al., 2011).

The variety and complexity of the apes' behaviors also provided another mechanism to explore their mental representations of their symbols, through vocabulary errors (analogous to speech errors, e.g., Fromkin, 1980). The premise of speech error research is that, like priming, specific information activates all associated knowledge in the brain. For example, exposure to the word rabbit makes it more likely a participant will spell the homophone h-a-r-e as opposed to h-a-i-r. Similarly, when making a speech error, people are much more likely to substitute related words than non-related words. For example, if you intend to say, "I'll see you in June," you are most likely to accidentally replace June with another month, like April or May (e.g., MacKay, 1980). If you do not substitute another month, you are still more likely 
to replace June with another label associated with time, like a day of the week. This is hierarchical categorical replacement, taken by researchers to indicate complex mental webs of information that are attached to the symbols in question (Fromkin, 1980; MacKay, 1980; Nelson, 1974). Other frequent speech errors similarly indicate the mental webs associated with symbols and can include functionally related terms (cereal and milk), auditorily related words, and visually related words or referents (so the printed word might resemble the erroneous word or the two referents might look alike, Fromkin, 1980; MacKay, 1980; Nelson, 1974). All these errors serve to inform scientists about the concepts that exist within the mind of the speaker.

To explore the possibility that similar concepts exist in the minds of the apes, an analysis of the errors Kanzi, Panbanisha, and Panpanzee made during vocabulary tests was undertaken (Lyn, 2007). Errors made during every vocabulary test for all three lexigram-using apes over ten years were coded for the types of associations found in humans including: categorical similarity, physical similarity (of referent and symbol), functional similarity, and auditory similarity of the English word. All three apes showed non-random patterns of errors with different conceptual association types found in the apes' errors significantly more often than in two different random distributions of generated "errors." For example, the apes made categorical errors (substituting locations for other locations or food for foods) more often than would be expected by chance. Apes also made more functionally-related errors (substitutions like milk for cereal and locations for the food found at those locations, Lyn, 2007).

These error types were not more or less likely across different sample modalities. The apes' vocabulary tests could present the target symbol as a picture, lexigram, or English word, although the target choice was always a lexigram. The data show that categorical confusions were the most likely no matter the sample type; however, objects that looked the same (orange-ball) could be confused when the sample was spoken English and referents that sounded the same (Jared-cherries) could be confused even when the sample was a lexigram (Lyn, 2007). What these findings indicate is that inside the mind of the symbol-competent apes exists a very complex, rich, and detailed web of mental representations and suggests that these representations are activated when any connecting piece is triggered.

This level of mental representation indicates that the apes' conceptual understanding meets all definitions of symbol use and comprehension. The symbols are abstract, culturally-determined and arbitrary. They refer to objects in the real world, even in the absence of those objects, and the symbols, their referents, physical structure, functional use and relationships between symbols are all represented and connected in the mind of the apes. These findings are even stronger when combined with findings like semantic rule-based combinations of symbols (Greenfield \& Savage-Rumbaugh, 1991; Lyn, Greenfield, Savage-Rumbaugh et al., 2011) and representational play (Lyn et al., 2006) in these apes.

All these findings, particularly taken together, should shift the discourse surrounding animal models of the evolution of language. Although, to date, that shift has yet to happen. While the evolutionary path of other language components (e.g., speech, syntax) may need to posit a biological leap in the human species, the mental capacity for semantic communication seems to be extant not only in our closest relatives, the great apes, but likely also such diverse animals as marine mammals and birds (Herman et al., 1993; Pepperberg, 1999). Recognition of these capacities means that, within the study of human language evolution, it is unnecessary to search for evolutionary pressures that led to the biological infrastructure for semanticity. Fruitful studies will focus instead on the environmental and social mechanisms for expressing these semantic capacities.

The animal communication studies of Seyfarth and Cheney ignited an entire field of study, reinvigorated the debates surrounding the evolution of human language, and changed the landscape of animal communication forever. Without their illustration of semantic communication in a wild monkey species, and regardless of the debate that still rages over terms and functional usage, the study of animal communication in all forms would not be where it is today and comparative language evolution research would be a much less rich arena for future study. 


\section{Acknowledgements}

Special thanks to the volunteers and research students who helped collect the data.

\section{References}

Brakke, K. E., \& Savage-Rumbaugh, E. S. (1995). The development of language skills in bonobo and chimpanzee I. Comprehension. Language and Communication, 15, 121-148.

Brakke, K. E., \& Savage-Rumbaugh, E. S. (1996). The development of language skills in Pan - II. Production. Language and Communication, 16, 361-380.

Burling, R. (1993). Primate calls, human language, and nonverbal communication. Current Anthropology, 34, 2553.

Collections of Peirce's Writings. (n.d.). Retrieved October 1, 2020, from http://www.helsinki.fi/science/commens/collections.html

Curtin, M. (2009). Indexical signs, identities and the linguistic landscape of Taipei. In Linguistic landscape: Expanding the scenery (pp. 221-237). Routledge.

Deacon, T. W. (1997). The symbolic species: The co-evolution of language and the brain. W. W. Norton.

Epstein, R., Lanza, R. P., \& Skinner, B. E. (1980). Symbolic communication between two pigeons (Columba livia domestica). Science, 207, 543-545.

Fitch, W. T. (2005). The evolution of language: A comparative review. Biology and Philosophy, 20, 193-230.

Fitch, W. T. (2010). The evolution of language. Cambridge University Press.

Fitch, W. T., \& Zuberbühler, K. (2013). Primate precursors to human language: Beyond discontinuity. In E. Altenmüller, S. Schmidt, \& E. Zimmermann (Eds.), The evolution of emotional communication: From sounds in nonhuman mammals to speech and music in man (pp. 26-48). Oxford University Press.

Fromkin, V. A. (1980). Introduction. In V. A. Fromkin (Ed.), Errors in linguistic performance: Slips of the tongue, ear, pen and hand (pp. 1-12). Mouton.

Gardner, R. A., \& Gardner, B. T. (1969). Teaching sign language to a chimpanzee. Science, 165, 664-672.

Gillespie-Lynch, K., Greenfield, P. M., Lyn, H., \& Savage-Rumbaugh, E. S. (2014). Gestural and symbolic development among apes and humans: Support for a multimodal theory of language evolution. Frontiers in Psychology, 5, 1-10.

Goldin-Meadow, S. (1993). When does gesture become language? A study of gesture used as a primary communication system by deaf children of hearing parents. In K. R. Gibson \& T. Ingold (Ed.), Tools, language and cognition in human evolution (pp. 63-85). Cambridge University Press.

Greenfield, P. M., \& Savage-Rumbaugh, E. S. (1991). Imitation, grammatical development, and the invention of protogrammar by an ape. In N. A. Krasnegor, D. M. Rumbaugh, R. L. Schiefelbusch, \& M. StuddertKennedy (Eds.), Biological and behavioral determinants of language development (pp. 235-258). Lawrence Erlbaum Associates, Inc.

Herman, L. M., \& Forestell, P. H. (1985). Reporting presence or absence of named objects by a language-trained dolphin. Neuroscience and Biobehavioral Reviews, 9, 667-681.

Herman, L. M., Matus, D. S., Herman, E. Y. K., Ivancik, M., \& Pack, A. A. (2001). The bottlenosed dophin's (Tursiops truncatus) understanding of gestures as symbolic representations of its body parts. Animal Learning and Behavior, 29, 250-264.

Herman, L. M., Pack, A. A., \& Morrel-Samuels, P. (1993). Representational and conceptual skills of dolphins. In H. L. Roitblat, L. M. Herman, \& P. E. Nachtigall (Eds.), Language and communication: Comparative perspectives (pp. 403-442). Lawrence Erlbaum Associates, Inc.

Herman, L. M., Richards, D. G., \& Wolz, J. P. (1984). Comprehension of sentences by bottlenosed dolphins. Cognition, 16, 129-219.

Hockett, C. F. (1960). The origin of speech. Scientific American, 203, 88-96.

Janik, V. M., \& Slater, P. J. B. (1997). Vocal learning in mammals. Advances in the Study of Behavior, 26, 59-99.

Lloyd, E. A. (2004). Kanzi, evolution, and language. Biology and Philosophy, 19, 577-588.

Lyn, H. (2007). Mental representation of symbols as revealed by vocabulary errors in two bonobos (Pan paniscus). Animal Cognition, 10, 461-475.

Lyn, H. (2012). Apes and the evolution of language: Taking stock of 40 years of research. In J. Vonk \& T. K. Shackelford (Eds.), Oxford handbook of comparative evolutionary psychology (pp. 356-378). Oxford University Press. 
Lyn, H. (2017). The question of capacity: Why enculturated and trained animals have much to tell us about the evolution of language. Psychonomic Bulletin and Review, 24, 85-90.

Lyn, H., Greenfield, P. M., \& Savage-Rumbaugh, E. S. (2006). The development of representational play in chimpanzees and bonobos: Evolutionary implications, pretense, and the role of interspecies communication. Cognitive Development, 21, 199-213.

Lyn, H., Greenfield, P. M., \& Savage-Rumbaugh, E. S. (2011). Semiotic combinations in Pan: A cross-species comparison of communication in a chimpanzee and a bonobo. First Language, 31, 300-325.

Lyn, H., Greenfield, P. M., Savage-Rumbaugh, E. S., Gillespie-Lynch, K., \& Hopkins, W. D. (2011). Nonhuman primates do declare! A comparison of declarative symbol and gesture use in two children, two bonobos, and a chimpanzee. Language and Communication, 31, 63-74.

Macedonia, J. M., \& Evans, C. S. (1993). Essay on contemporary issues in ethology: Variation among mammalian alarm call systems and the problem of meaning in animal signals. Ethology, 93, 177-197.

MacKay, D. G. (1980). Speech errors: Retrospect and prospect. In V. A. Fromkin (Ed.), Errors in linguistic perfomance: Slips of the tongue, ear, pen and hand (pp. 319-332). Academic Press.

Manser, M. B. (2013). Semantic communication in vervet monkeys and other animals. Animal Behaviour, 86, 491496.

Miles, H. L. (1994). Me Chantek: The development of self-awareness in a signing orangutan. In S. T. Parker, R. W. Mitchell, \& M. L. Boccia (Eds.), Self-awareness in animals and humans: Developmental perspectives (pp. 254-272). Cambridge University Press.

Nelson, K. (1974). Concept, word, and sentence: Interrelations in acquisition and development. Psychological Review, 81, 267-285.

Patterson, F. G., \& Linden, E. (1981). The education of Koko. Holt, Rinehart and Winston.

Pepperberg, I. M. (1999). The Alex studies: Cognitive and communicative abilities of grey parrots. Harvard University Press.

Pepperberg, I. M. (2017). Animal language studies: What happened? Psychonomic Bulletin and Review, 24, 181185.

Premack, D., \& Premack, A. J. (1983). The mind of an ape (1st ed.). Norton.

Ristau, C. A., \& Robbins, D. (1982). Language in the great apes: A critical review. In J. S. Rosenblatt, R. A. Hinde, \& C. Beer (Eds.), Advances in the study of behavior (Vol. 12). Academic Press.

Roitblat, H. L., Herman, L. M., \& Nachtigall, P. E. (Eds). (1993). Language and communication: Comparative perspectives. Lawrence Erlbaum Associates, Inc.

Rumbaugh, D. M. (1977). Language learning by a chimpanzee: The Lana project. Academic Press.

Savage-Rumbaugh, E. S. (1981). Can apes use symbols to represent their world? Annals of the New York Academy of Sciences, 364, 35-59.

Savage-Rumbaugh, E. S. (1986). Ape language: From conditioned response to symbol. Columbia University Press.

Savage-Rumbaugh, E. S., McDonald, K., Sevcik, R. A., Hopkins, W. D., \& Rupert, E. (1986). Spontaneous symbol acquisition and communicative use by pygmy chimpanzees (Pan paniscus). Journal of Experimental Psychology: General, 115, 211-235.

Savage-Rumbaugh, E. S., Murphy, J., Sevcik, R. A., Brakke, K. E., Williams, S. L., \& Rumbaugh, D. M. (1993). Language comprehension in ape and child. Monographs of the Society for Research in Child Development, $58, \mathrm{v}-221$.

Savage-Rumbaugh, E. S., \& Rumbaugh, D. M. (1980). Requisites of symbolic communication. The Psychological Record, 30, 305-318.

Savage-Rumbaugh, E. S., Rumbaugh, D. M., \& Boysen, S. (1978). Symbolic communication between two chimpanzees (Pan troglodytes). Science, 201, 641-644.

Savage-Rumbaugh, E. S., Rumbaugh, D. M., Smith, S. T., \& Lawson, J. (1980). Reference: The linguistic essential. Science, 210, 922-925.

Senghas, A. (2003). Intergenerational influence and ontogenetic development in the emergence of spatial grammar in Nicaraguan Sign Language. Cognitive Development, 18, 511-531.

Seyfarth, R. M., Cheney, D. L., \& Marler, P. (1980). Vervet monkey alarm calls: Semantic communication in a freeranging primate. Animal Behaviour, 28, 1070-1094.

Smith, W. J. (1977). The behavior of communicating: An ethological approach. Harvard University Press.

Smith, K., \& Kirby, S. (2008). Cultural evolution: Implications for understanding the human language faculty and its evolution. Philosophical Transactions of the Royal Society B: Biological Sciences, 363, 3591-3603.

Taglialatela, J. P., Reamer, L., Schapiro, S. J., \& Hopkins, W. D. (2012). Social learning of a communicative signal in captive chimpanzees. Biology Letters, 8, 498-501. 
Taglialatela, J. P., Russell, J. L., Schaeffer, J. A., \& Hopkins, W. D. (2011). Chimpanzee vocal signaling points to a multimodal origin of human language. PloS One, 6, e18852.

Terrace, H. S. (1979). Nim (1st ed.). Knopf.

Wheeler, B. C., \& Fischer, J. (2012). Functionally referential signals: A promising paradigm whose time has passed. Evolutionary Anthropology, 21, 195-205. 